\title{
Pancreatic Intraductal Tubulopapillary Neoplasm
}

National Cancer Institute

\section{Source}

National Cancer Institute. Pancreatic Intraductal Tubulopapillary Neoplasm. NCI

Thesaurus. Code C95506.

An epithelial neoplasm that arises from the exocrine pancreas characterized by the formation of tubular structures, high grade dysplasia, and ductal differentiation. Grossly, it is characterized by the presence of intraductal nodular masses. Morphologically, there are nodules of tubular glands and occasional papillary structures growing in dilated ducts. There is no significant mucin production. Signs and symptoms include epigastric pain, weight loss, vomiting, steatorrhea, and diabetes mellitus. 